\title{
ANALISIS DAYA DUKUNG DAN PENURUNAN PONDASI TIANG BOR DENGAN PLAXIS 3D TERHADAP HASIL LOADING TEST
}

\author{
Dewi Sartika Hutapea, Roesyanto, Rudi Iskandar
}

Universitas Sumatera Utara (USU) Medan Sumatera Utara. Indonesia

Email: miss.pea13@yahoo.co.id, roesyantos@yahoo.com, sipil.s2.usu@gmail.com

\begin{tabular}{l} 
INFO ARTIKEL \\
\hline Diterima \\
17 Juni 2021 \\
Direvisi \\
18 Juni 2021 \\
Disetujui \\
21 Juni 2021 \\
\hline
\end{tabular}

Keywords: carrying capacity, drop, bored pile

\begin{abstract}
In the foundation analysis, the magnitude of the carrying capacity and the decrease that occurred are two of the most important things considering its function as the distribution of the load of a construction to the ground. The foundation must have a carrying capacity that is able to carry the load on it so that the load transfer system to the ground can run while controlling against the decrease in permits to maintain the stability of construction on it. This analysis aims to calculate the amount of carrying capacity and decrease that occurs on the foundation bored pile project Jakarta LRT-Corridor 1 (Phase 1) Kelapa Gading-Velodrome-Package P 102 with element method up to using Plaxis $3 D$ software with all mesh types. Based on the analysis that has been done, the carrying capacity of the ultimate bored pile with the interpretation method loading test with Davisson method provides a value of 816 tons, mazurkiewich method 950 tons and Chin method 761 tons. Plaxis 3D analysis produced a carrying capacity of 400 tons with davisson method, 816 tons with Mazurkiewich method and 766 tons with Chin method. So it can be concluded that the carrying capacity value based on Plaxis $3 D$ is greater than the results of loading tests in the field. While the decrease produced by the analysis of Plaxis $3 D$ with medium mesh provides the closest value to the test results in the field.
\end{abstract}

\begin{abstract}
ABSTRAK
Dalam analisis pondasi, besarnya daya dukung dan penurunan yang terjadi merupakan dua hal terpenting mengingat fungsinya sebagai distribusi beban sebuah konstruksi ke tanah. Pondasi harus memiliki daya dukung yang mampu memikul beban diatasnya sehingga sistem tranfer beban ke tanah dapat berjalan dengan tetap mengontrol terhadap penurunan ijin untuk menjaga
\end{abstract}

$\begin{array}{llllll}\text { How to cite: } & \text { Hutapea Dewi Sartika, dkk (2021) Analisis Daya Dukung dan Penurunan Pondasi Tiang Bor dengan } \\ & \text { Plaxis 3D terhadap Hasil Loading } & \text { Test. Jurnal Syntax Admiration 2(6). } \\ & \text { https://doi.org/10.46799/jsa.v2i6.255 } & & & & \\ \text { E-ISSN: } & 2722-5356 & & & & \\ \text { Published by: } & \text { Ridwan Institute } & & & & \\ \end{array}$




\begin{tabular}{ll}
\hline kestabilan konstruksi di atasnya. Analisis ini bertujuan \\
untuk menghitung besarnya daya dukung dan penurunan \\
yang terjadi pada pondasi bored pile proyek Jakarta LRT- \\
Corridor 1 (Phase 1) Kelapa Gading-Velodrome-Package \\
P 102 dengan metode elemen hingga menggunakan \\
perangkat lunak Plaxis 3D dengan semua tipe mesh. \\
Berdasarkan analisis yang telah dilakukan, daya dukung \\
ultimate bored pile dengan metode interpretasi loading \\
test dengan metode Davisson memberikan nilai 816 ton, \\
metode Mazurkiewich 950 ton dan metode Chin 761 ton. \\
Analisis Plaxis 3D menghasilkan daya dukung 400 ton \\
dengan metode Davisson, 816 ton dengan metode \\
Mazurkiewich dan 766 ton dengan metode Chin. \\
Sehingga dapat disimpulkan bahwa nilai daya dukung \\
berdasarkan Plaxis 3D lebih besar daripada hasil loading \\
test di lapangan. Sedangkan penurunan yang dihasilkan \\
oleh analisis Plaxis 3D dengan mesh medium \\
memberikan nilai yang paling mendekati hasil pengujian \\
di lapangan.
\end{tabular}

\section{Pendahuluan}

Pondasi ialah bagian dari suatu sistem rekayasa yang meneruskan beban yang ditopang oleh pondasi dan beratnya sendiri kepada dan ke dalam tanah dan batuan yang terletak dibawahnya (Bowles, 1997). Suatu perencanaan pondasi dikatakan benar apabila beban yang diteruskan oleh pondasi ke tanah tidak melampaui kekuatan tanah yang bersangkutan (Das et al., 1995).

Pondasi tiang bor adalah suatu pondasi yang dibangun dengan mengebor tanah terlebih dahulu, lalu kemudian diisi dengan tulangan dan dicor. Tiang bor biasanya dipakai pada tanah yang stabil dan kaku, sehingga memungkinkan untuk membentuk lubang yang stabil dengan alat bor. Jika tanah mengandung air, pipa besi dibutuhkan untuk menahan dinding lubang dan pipa ditari ke atas pada waktu pengecoran. Pada tanah keras atau batuan lunak, dasar tiang dapat dibesarkan untuk menambah tahanan dukung ujung tiang.

Masalah dalam perencanaan pondasi yang perlu dianalisis adalah terkait dua hal, yakni daya dukung dan penurunan. Pondasi harus memiliki daya dukung yang cukup untuk menopang beban yang ada diatasnya baik beban dari struktur konstruksi maupun beban luar yang memengaruhi konstrusi tersebut. Selain itu Batasan penurunan yang terjadi pada pondasi juga perlu dijaga untuk kestabilan struktur atas konstruksi. Kedua hal tersebut dapat dilakukan dengan perhitungan secara empiris dan metode elemen hingga saat proses perencanaan dan monitoring saat proses pelaksanaan dengan pengujian pembebanan untuk mendapatkan daya dukung dan batas penurunan sesuai rencana.

Metode elemen hingga adalah metode yang membagi-bagi daerah yang akan dianalisis menjadi bagian-bagian yang kecil yang disebut dengan elemen. Plaxis merupakan suatu rangkuman program elemen hingga yang telah dikembangkan untuk 
menganalisa deformasi dan stabilitas geoteknik dalam perencanaan sipil. Salah satu masalah yang dapat diselesaikan oleh Plaxis adalah interaksi tanah dengan pondasi. Sehingga Plaxis dapat digunakan dalam menganalisis daya dukung dan penurunan pondasi.

(Prakasa \& Rijaluddin, 2016) dalam penelitiannya telah menganalisis daya dukung dan penurunan pondasi tiang bor tunggal dengan menggunakan program Plaxis. Hasil analisis tersebut adalah nilai daya dukung dan penurunan yang diperoleh dari analisis Plaxis dan rumus empiris dari metode Reese dan Wrigth adalah mendekati.

Dalam pengaplikasiannya Plaxis membutuhkan pemodelan struktur dan input material konstruksi yang dimodelkan. Selain itu tahapan konstruksi di lapangan juga diinterpretasikan dalam analisa Plaxis sehingga didapatkan hasil yang sesuai dengan kondisi di lapangan. Pemilihan tipe mesh serta jumlah titik nodal juga menjadi pertimbangan untuk mendapatkan hasil yang akurat. Untuk mengetahui seberapa besar pengaruh pemilihan input jenis mesh dan titik nodal serta ketelitian dan sebagainya terhadap hasil pemodelan Plaxis maka penulis melakukan penelitian ini. Penelitian ini bertujuan untuk mengetahui pengaruh data input Plaxis terhadap daya dukung dan penurunan pondasi hasil perencanaan yang dilakukan secara analitis dan hasil pengujian monitoring di lapangan untuk mendapatkan pemodelan 3D yang memberikan hasil yang akurat pada analisis pondasi.

(Mansur et al., 2019) menganilisis kapasitas dukung dan penurunan tiang bor tunggal akibat beban gempa dengan menggunakan Plaxis 2D. Berdasarkan hasil analisis diperoleh kapasitas dukung pondasi terhadap gaya tekan berdasarkan data SPT adalah 109,29 ton. Adapun penurunan yang terjadi tanpa adanya beban gempa adalah 23,86 $\mathrm{mm}$. penurunan yang terjadi dengan memperhitungkan beban gempa dengan magnitude 5,2 SR, 6 SR, 7 SR dan 8 SR berturut-turut adalah 153,44 mm, 178,71 mm, 234,58 mm dan 234,64 $\mathrm{mm}$. Penurunan tiang bor dengan beban gempa lebih besar daripada penurunan ijin tiang yang disyaratkan yaitu $40 \mathrm{~mm}$.

(Harsanto et al., 2015) dalam tulisannya, memberikan hasil analisis daya dukung tiang bor pada struktur pylon jembatan Soekarno dengan Plaxis 3D. Adapun hasil analisis yang telah dilakukan adalah daya sukung axial Plaxis 3D dari daya dukung axial statis dengan persentase sebesar 13,77\%, daya dukung lateral plaxis 3D lebih kecil dari daya dukung lateral statis dengan selisih persentase sebesar 21.79\%, Momen Plaxis 3D lebih kecil daripada momen statis dengan selisih persentase $11.85 \%$ dan settlement Plaxis 3D lebih kecil dari settlement statis dengan selisih persentase 6.02\%.

(Fadilah \& Tunafiah, 2018) melakukan analisa daya dukung bored pile berdasarkan data N-SPT menurut rumus Reese dan Wright dan penurunannya. Berdasarkan hasil perhitungan, daya dukung yang dihitung dengan rumus tersebut lebih kecil daripada daya dukung yang diberikan pada data PDA.

(Mugiono et al., 2020) melakukan analisis perbandingan daya dukung pondasi tiang bored pile dari hasil tes PDA berdasarkan metode Chin, Mazurkiewich dan Davisson. Berdasarkan hasil analisis yang dilakukan, dapat disimpulkan bahwa hasil dari pengujian PDA lebih kecil dari analisis aplikasi Allpile. Hal ini bisa disebabkan 
karena pada saat pengujian PDA, proses transfer energi dari palu kurang efektif atau beban dari palu kurang sehingga nilai daya dukung dan penurunan yang tercatat selama pengujian lebih kecil dan membentuk kurva yang kurang sempurna dikarenakan proses transfer energi yang kurang sempurna.

\section{Metode Penelitian}

Dalam penelitian ini, analisis dilakukan menggunakan data yang diperoleh dari proyek Jakarta LRT-Coridor 1 (Phase 1) Kelapa Gading-Velodrome-Package P 102. Data yang diperoleh berupa layout pekerjaan pondasi bored pile, hasil penyelidikan tanah dari borring dan hasil loading test.

Analisis dilakukan dengan melakukan perhitungan daya dukung dengan interpretasi dari data loading test di lapangan dengan metode Davisson, Chin dan Mazurkiewich. Selanjutnya dilakukan analisis dengan metode elemen hingga menggunakan Plaxis 3D. Analisis dilakukan dengan melakukan pemodelan sesuai dengan proses loading test di lapangan dengan besar dan waktu pembebanan yang sama. Analisis Plaxis dilakukan menggunakan tiga jenis mesh yang berbeda yaitu mesh medium, fine dan very fine.

Hasil yang diberikan oleh Plaxis 3D adalah besarnya penurunan yang dihasilkan dari proses pembebanan yang dilakukan. Dari besar penurunan tersebut dilakukan perhitungan daya dukung dengan interpretasi metode Davisson, Chin dan Mazurkiewich seperti pada hasil loading test. Nilai daya dukung ini yang nantinya akan dibandingkan dengan hasil daya dukung dari data penurunan loading test untuk dianalisis. Tidak hanya itu, besar penurunan yang terjadi dari hasil Plaxis 3D juga akan dibandingkan dengan data penurunan loading test yang dilakukan di lapangan..

\section{Hasil dan Pembahasan}

1. Daya Dukung Berdasarkan Data Loading Test

Perhitungan daya dukung dilakukan menggunakan metode interpretasi dari Davisson, Chin dan Mazurkiewich. Data yang digunakan untuk perhitungan adalah hasil loading test di lapangan. Data tersebut disajikan pada Tabel 1.

\section{Tabel 1}

Data loading test di lapangan

\begin{tabular}{|c|c|c|c|c|c|}
\hline \multirow{2}{*}{ No } & \multirow{2}{*}{ Siklus } & \multirow{2}{*}{$\begin{array}{c}\text { Waktu } \\
\text { (jam) }\end{array}$} & \multicolumn{2}{|c|}{ Pembebanan } & \multirow{2}{*}{$\begin{array}{c}\text { Penurunan } \\
(\mathbf{m m})\end{array}$} \\
\hline & & & $(\%)$ & (ton) & \\
\hline 1 & \multirow{5}{*}{1} & 0,00 & 0 & 0 & 0 \\
\hline 2 & & 1,17 & 25 & 102 & 0,14 \\
\hline 3 & & 2,08 & 50 & 204 & 0,33 \\
\hline 4 & & 2,67 & 25 & 102 & 0,18 \\
\hline 5 & & 3,75 & 0 & 0 & 0,12 \\
\hline 6 & \multirow{5}{*}{2} & 4,17 & 50 & 204 & 0,4 \\
\hline 7 & & 5,25 & 75 & 306 & 0,62 \\
\hline 8 & & 6,33 & 100 & 408 & 0,85 \\
\hline 9 & & 6,75 & 75 & 306 & 0,67 \\
\hline 10 & & 7,17 & 50 & 204 & 0,49 \\
\hline
\end{tabular}


Analisis Daya Dukung dan Penurunan Pondasi Tiang Bor dengan Plaxis 3D terhadap Hasil Loading Test

\begin{tabular}{|c|c|c|c|c|c|}
\hline \multirow{2}{*}{ No } & \multirow{3}{*}{ Siklus } & \multirow{2}{*}{$\begin{array}{c}\text { Waktu } \\
\text { (jam) }\end{array}$} & \multicolumn{2}{|c|}{ Pembebanan } & \multirow{2}{*}{$\begin{array}{c}\text { Penurunan } \\
(\mathbf{m m})\end{array}$} \\
\hline & & & $(\%)$ & (ton) & \\
\hline 11 & & 8,25 & 0 & 0 & 0,17 \\
\hline 12 & \multirow{8}{*}{3} & 8,67 & 50 & 204 & 0,42 \\
\hline 13 & & 9,08 & 100 & 408 & 0,9 \\
\hline 14 & & 10,17 & 125 & 510 & 1,17 \\
\hline 15 & & 11,25 & 150 & 612 & 1,51 \\
\hline 16 & & 11,67 & 125 & 510 & 1,38 \\
\hline 17 & & 12,08 & 100 & 408 & 1,18 \\
\hline 18 & & 12,50 & 50 & 204 & 0,84 \\
\hline 19 & & 13,58 & 0 & 0 & 0,3 \\
\hline 20 & \multirow{9}{*}{4} & 14,00 & 50 & 204 & 1,02 \\
\hline 21 & & 14,42 & 100 & 408 & 2,33 \\
\hline 22 & & 14,83 & 150 & 612 & 2,79 \\
\hline 23 & & 15,92 & 175 & 714 & 3,24 \\
\hline 24 & & 28,00 & 200 & 816 & 4,26 \\
\hline 25 & & 29,08 & 150 & 612 & 3,61 \\
\hline 26 & & 30,17 & 100 & 408 & 3,1 \\
\hline 27 & & 31,25 & 50 & 204 & 2,46 \\
\hline 28 & & 33,33 & 0 & 0 & 1,35 \\
\hline
\end{tabular}

Berdasarkan pengujian loading test di lapangan, dihasilkan grafik hubungan beban dan penurunan yang disajikan pada Gambar 1 .

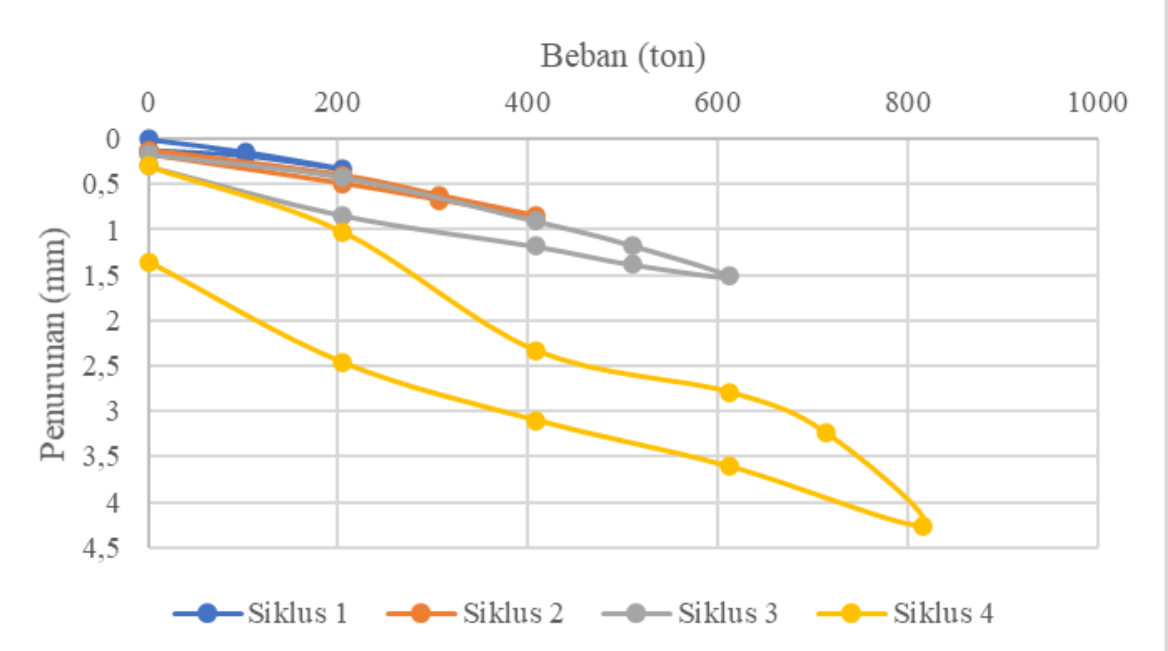

Gambar 1

Grafik Hubungan Beban dan Penurunan dari Hasil Pengujian Loading Test

a. Perhitungan dengan Metode Davisson (1973)

Perhitungan daya dukung aksial bored pile berdasarkan metode Davisson adalah sebagai berikut.
Diameter tiang
$=1,2 \mathrm{~m}$
Panjang tiang
$=23,8 \mathrm{~m}$ 
Dewi Sartika Hutapea, Roesyanto, Rudi Iskandar

$\begin{array}{ll}\text { Luas tiang } & =1,13 \mathrm{~m} 2 \\ \text { Beban rencana } & =408 \text { ton } \\ \text { Beban uji } & =816 \mathrm{ton} \\ \text { f'c } & =30 \mathrm{MPa}\end{array}$

$\mathrm{E}=4700 \sqrt{30}=25.742,96 \mathrm{MPa}=2.574 .296$ ton $/ \mathrm{m} 2$

$\Delta=\frac{408 \text { ton } \mathrm{x} 23,8 \mathrm{~m}}{2.574 .296 \text { ton } / \mathrm{m}^{2} \times 1,13 \mathrm{~m}^{2}}=0,0033 \mathrm{~m}=3,3 \mathrm{~mm}$

$X=0,15+47,24 / 120$ inch $=10,15 \mathrm{~mm}$

Adapun hasil perhitungan penurunan yang terjadi pada setiap pembebanan disajikan pada Tabel 2.

Tabel 2

Perhitungan Beban-Penurunan Metode Davisson

\begin{tabular}{llll}
\hline Beban (ton) & $\begin{array}{c}\text { Penurunan } \\
\text { Maksimum }(\mathbf{m m})\end{array}$ & delta & delta $+\mathbf{X}$ \\
\hline 0 & 0 & 0,00 & 10,15 \\
\hline 102 & 0,14 & 0,83 & 10,98 \\
\hline 204 & 0,4 & 1,67 & 11,82 \\
\hline 408 & 0,9 & 3,34 & 13,49 \\
\hline 612 & 2,97 & 5,01 & 15,16 \\
\hline 816 & 4,26 & 6,67 & 16,82 \\
\hline
\end{tabular}

Nilai daya dukung bored pile dapat ditentukan dari grafik beban dan penurunan yang diperoleh dari perhitungan di atas. Grafik tersebut disajikan pada Gambar 2.

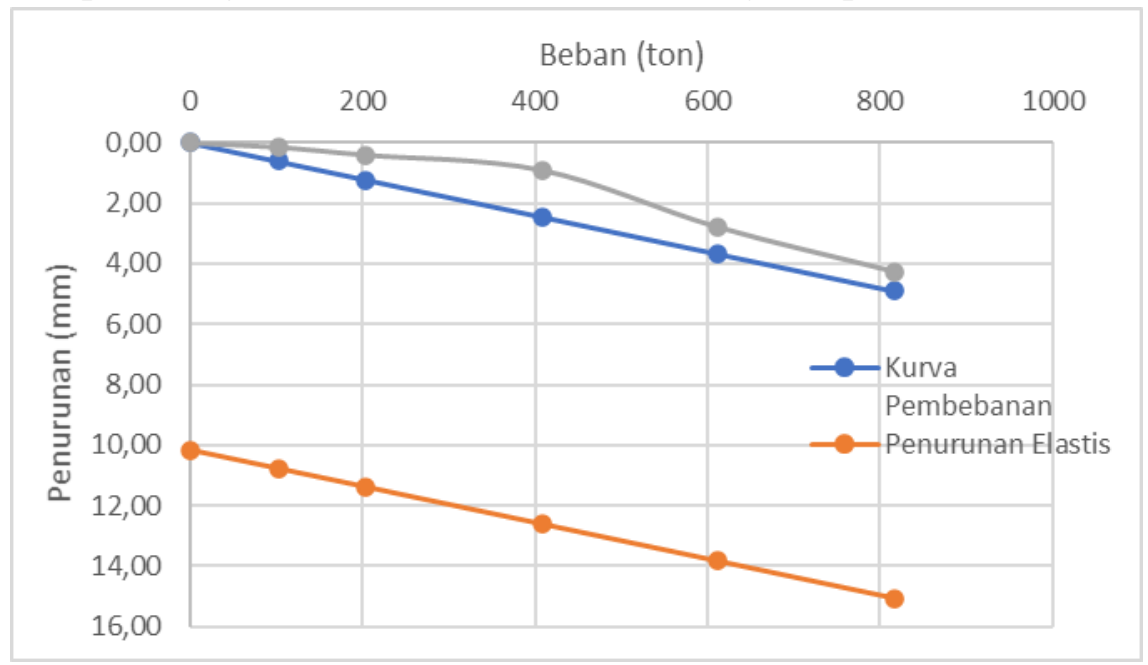

Gambar 2

Grafik Hasil Perhitungan Daya Dukung dengan Metode Davisson

Berdasarkan Gambar 2 dianggap garis penurunan saat pembebanan maksimum sudah mendekati dengan penurunan elastis sehingga dapat disimpulkan bahwa besar daya dukung bored pile dari interpretasi loading test dengan metode Davisson adalah 816 ton. 
Analisis Daya Dukung dan Penurunan Pondasi Tiang Bor dengan Plaxis 3D terhadap Hasil Loading Test

a. Perhitungan dengan Metode Mazurkiewich (1972)

Interpretasi daya dukung dengan metode Mazurkiewichz dilakukan menggunakan grafik hubungan beban dan penurunan yang terjadi saat pelaksanaan loading test. Nilai beban dan penurunan yang digunakan dilampirkan pada Tabel 4 yang kemudian disajikan dalam bentuk grafik pada Gambar 3 yang akan digunakan untuk interpretasi daya dukung bored pile.

Tabel 3

Nilai Beban dan Penurunan Dari Data Loading Test

\begin{tabular}{cc} 
Beban (ton) & $\begin{array}{c}\text { Penurunan } \\
\text { Maksimum }(\mathrm{mm})\end{array}$ \\
\hline 0 & 0 \\
\hline 204 & 2,46 \\
\hline 408 & 3,1 \\
\hline 612 & 3,61 \\
\hline 816 & 4,26 \\
\hline
\end{tabular}

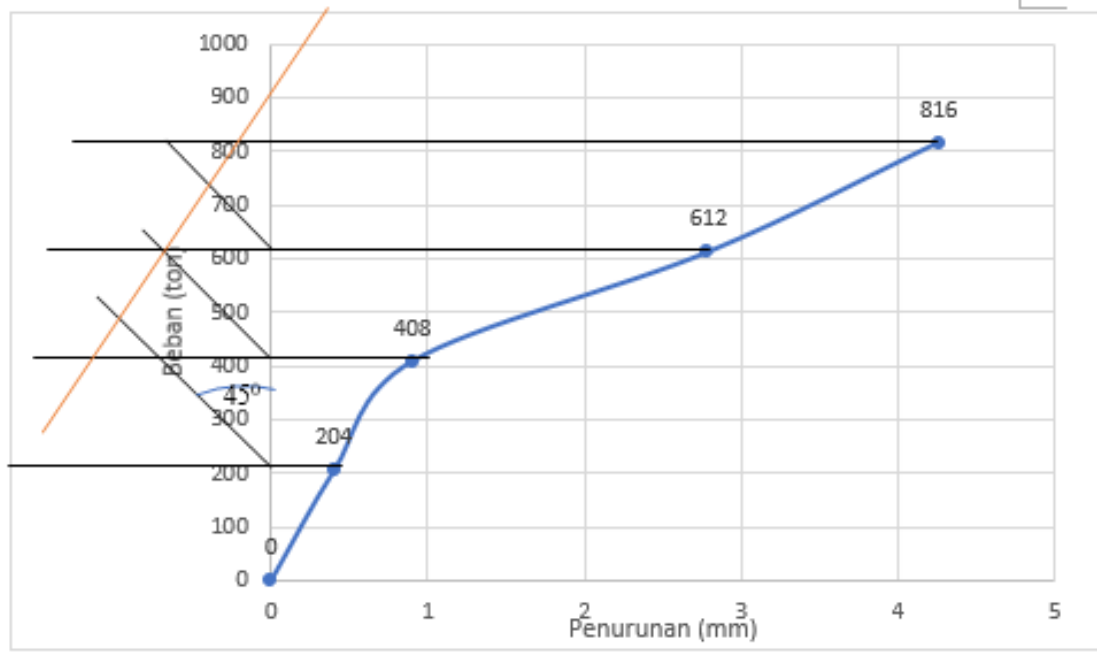

\section{Gambar 3}

Interpretasi Daya Dukung Aksial Bored Pile dengan Metode Mazurkiewich

Berdasarkan Gambar 3, hasil interpretasi daya dukung yang telah dilakukan, didapat besar daya dukung aksial bored pile dengan metode Mazurkiewich adalah 950 ton.

a. Perhitungan dengan Metode Chin (1972)

Interpretasi daya dukung aksial bored pile dengan metode Chin adalah menggunakan perbandingan penurunan tehadap beban. Kemudian dilakukan regresi linier untuk mendapatkan persamaan garis lurus dari bebarapa kordinat titik. Dengan memasukkan beban maksimum akan diperoleh daya dukung maksimum (ultimate) dari bored pile. Interpretasi dengan metode Chin (1971) disajikan pada Tabel 4 berikut. 
Tabel 4

Perhitungan Beban-Penurunan Metode Chin

\begin{tabular}{|c|c|c|c|c|c|c|}
\hline $\begin{array}{l}\text { Penurunan } \\
(\mathbf{m m})\end{array}$ & Beban (ton) & Penurunan/Beban & $\mathbf{S}(\mathbf{x})$ & $\mathrm{S} / \mathrm{Q}(\mathrm{y})$ & $\mathbf{X}^{2}$ & $\mathbf{X Y}$ \\
\hline 0 & 0 & 0,000 & 0 & 0,000 & 0,00 & 0,000 \\
\hline 0,33 & 204 & 0,002 & 0,33 & 0,002 & 0,11 & 0,001 \\
\hline 0,62 & 306 & 0,002 & 0,62 & 0,002 & 0,38 & 0,001 \\
\hline 0,85 & 408 & 0,002 & 0,85 & 0,002 & 0,72 & 0,002 \\
\hline 1,17 & 510 & 0,002 & 1,17 & 0,002 & 1,37 & 0,003 \\
\hline 1,51 & 612 & 0,002 & 1,51 & 0,002 & 2,28 & 0,004 \\
\hline 3,24 & 714 & 0,005 & 3,24 & 0,005 & 10,50 & 0,015 \\
\hline 4,26 & 816 & 0,005 & 4,26 & 0,005 & 18,15 & 0,022 \\
\hline \multicolumn{3}{|c|}{ Total } & 11,98 & 0,02 & 33,51 & 0,05 \\
\hline
\end{tabular}

Regresi linier:

$$
\begin{aligned}
& \mathrm{a} \quad=\frac{\left(\Sigma_{y} \cdot \Sigma x^{2}\right)-(\Sigma x \cdot \Sigma x y)}{n \cdot \Sigma x^{2}-(\Sigma x)^{2}}=0,00093 \\
& \mathrm{~b} \quad=\frac{n \cdot \Sigma x y-\Sigma x \cdot \Sigma y}{n \cdot \Sigma x^{2}-(\Sigma x)^{2}}=0,0011 \\
& \text { diperoleh persamaan garis lurus: } \mathrm{y}=0,0011 \mathrm{x}+0,00093
\end{aligned}
$$

Hasil regresi linier tersebut disajikan pada grafik yang dimuat pada Gambar 4

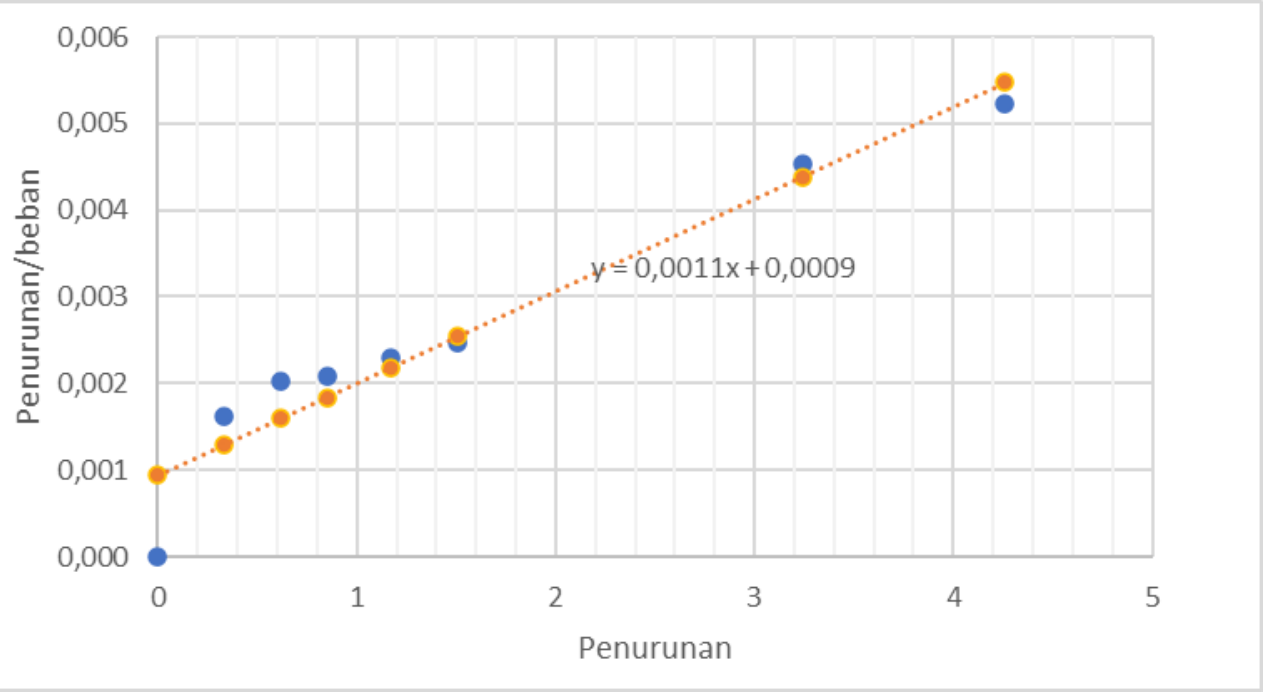

\section{Gambar 4}

\section{Grafik Interpretasi Metode Chin}

Besar daya dukung ultimate dengan metode Chin dihitung dengan cara berikut:

$$
\begin{aligned}
& \mathrm{y}=0,0011(4,26)+0,0009=0,0056 \\
& \mathrm{y}=\mathrm{S} / \mathrm{Q} \\
& \mathrm{Q}=\frac{4,26}{0,0056}=760,71 \approx 761 \text { ton } \\
& \mathrm{Q}_{\mathrm{ijin}}=761 / 2=380,5 \text { ton }
\end{aligned}
$$


Jadi, dengan metode Chin didapatkan daya dukung ultimate tiang bor sebesar 761 ton.

\section{Analisis Metode Elemen Hingga dengan Plaxis 3D}

Analisis selanjutnya dilakukan dengan metode elemen hingga menggunakan Plaxis. Analisis akan dilakukan pada Plaxis 3D dengan variasi pemodelan seperti yang telah dijelaskan pada tujuan penelitian. Dalam analisis Plaxis 3D membutuhkan nilai parameter tanah eksisting dan parameter bored pile yang akan digunakan sebagai input dari proses analisis yang dilakukan. Selain itu tahapan pembebanan saat pengujian loading test akan diinterpretasikan dalam tahapan stage construction sehingga didapatkan nilai daya dukung dan penurunan yang mendekati dengan nilai di lapangan. Karena keterbatasan data pengujian laboratorium, maka parameter tanah eksisting diperoleh dari korelasi dengan jenis tanah dan nilai SPT dari borlog BL05. Adapun hasil korelasi tersebut disajikan pada Tabel 5

\section{Tabel 5}

Parameter Material yang Digunakan Untun Input Plaxis

\begin{tabular}{|c|c|c|c|c|c|c|c|c|c|}
\hline Parameter & Lapisan 1 & Lapisan 2 & Lapisan 3 & Lapisan 4 & $\begin{array}{c}\text { Lapisan } \\
5\end{array}$ & $\begin{array}{c}\text { Lapisan } \\
6\end{array}$ & Lapisan 7 & Lapisan 8 & $\begin{array}{l}\text { Bored } \\
\text { pile }\end{array}$ \\
\hline $\begin{array}{l}\text { Jenis } \\
\text { Tanah }\end{array}$ & Lempung & Lanau & $\begin{array}{l}\text { Lempung } \\
\text { berlanau }\end{array}$ & $\begin{array}{c}\text { Lanau } \\
\text { berlempun } \\
\mathrm{g}\end{array}$ & $\begin{array}{c}\text { Pasir } \\
\text { bersemen }\end{array}$ & $\begin{array}{l}\text { Lempung } \\
\text { berlanau }\end{array}$ & $\begin{array}{c}\text { Lanau } \\
\text { bersemen }\end{array}$ & Lempung & \\
\hline $\begin{array}{l}\text { Kedalaman } \\
\text { lapisan }(\mathrm{m})\end{array}$ & 10 & 8 & 1 & 6,5 & 5,5 & 2 & 2 & 15 & 15 \\
\hline $\begin{array}{c}\text { Material } \\
\text { model }\end{array}$ & $\begin{array}{c}\text { Mohr- } \\
\text { Coulomb }\end{array}$ & $\begin{array}{c}\text { Mohr- } \\
\text { Coulomb }\end{array}$ & $\begin{array}{c}\text { Mohr- } \\
\text { Coulomb }\end{array}$ & $\begin{array}{c}\text { Mohr- } \\
\text { Coulomb }\end{array}$ & $\begin{array}{c}\text { Mohr- } \\
\text { Coulomb }\end{array}$ & $\begin{array}{c}\text { Mohr- } \\
\text { Coulomb }\end{array}$ & $\begin{array}{c}\text { Mohr- } \\
\text { Coulomb }\end{array}$ & $\begin{array}{r}\text { Mohr- } \\
\text { Coulomb }\end{array}$ & $\begin{array}{l}\text { Linear } \\
\text { elastic }\end{array}$ \\
\hline Tipe & Undrained & Undrained & Undrained & Undrained & Drained & Drained & $\begin{array}{c}\text { Undraine } \\
\text { d }\end{array}$ & Undrained & $\begin{array}{l}\text { Non- } \\
\text { Porous }\end{array}$ \\
\hline $\begin{array}{c}Y_{\operatorname{sir}} \\
\left(\mathrm{kN} / \mathrm{m}^{3}\right)\end{array}$ & 14 & 16 & 18,5 & 19 & 17,5 & 17 & 17,5 & 18 & - \\
\hline $\begin{array}{c}Y_{d \sigma} \\
\left(\mathrm{kN} / \mathrm{m}^{3}\right)\end{array}$ & 4,2 & 6,2 & 8,7 & 9,2 & 7,7 & 7,2 & 7,7 & 8,2 & 24 \\
\hline $\mathrm{c}\left(\mathrm{kN} / \mathrm{m}^{2}\right)$ & 12,5 & 27 & 20 & 22 & 2 & 20 & 22 & 24 & - \\
\hline$\Phi\left({ }^{0}\right)$ & 1 & 1 & 1 & 1 & 27 & 1 & 1 & 1 & - \\
\hline$\Psi\left({ }^{0}\right)$ & - & - & - & - & - & - & - & - & - \\
\hline $\mathrm{E}\left(\mathrm{kN} / \mathrm{m}^{2}\right)$ & 3000 & 6000 & 5500 & 4800 & 9000 & 5200 & 4700 & 4500 & 25742960 \\
\hline$\mu$ & 0,2 & 0,2 & 0,2 & 0,2 & 0,2 & 0,2 & 0,2 & 0,2 & 0,1 \\
\hline
\end{tabular}

Analisis Plaxis 3D dilakukan dengan memodelkan bored pile secara utuh sesuai kondisi sebenarnya. Adapun langkah analisis yang dilakukan adalah sebagai berikut.

\section{Project properties}

Pada tahapan ini dilakukan pengaturan umum yang akan digunakan pada analisis ini. Pengaturan yang akan digunakan disajikalan pada Gambar 6. 


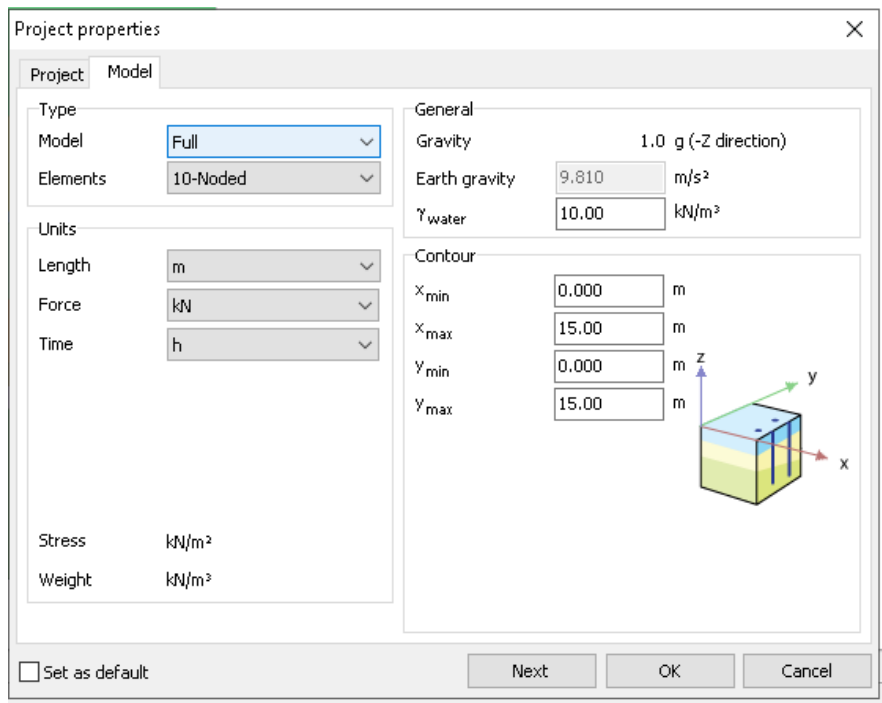

\section{Gambar 5}

2. Soil

\section{Project Properties yang Digunakan Saat Analisis}

Langkah selanjutnya dalah memodelkan bore hole tanah eksisting sesuai data dari penyelidikan tanah. Tidak hanya memodelkan, parameter tanah yang digunakan juga dideklarsikan pada tahapan ini. Parameter bored pile yang digunakan juga diinput pada tahapan ini. Adapun proses pemodelan dan input parameter tanah dan bored pile disajikan pada Gambar 7.

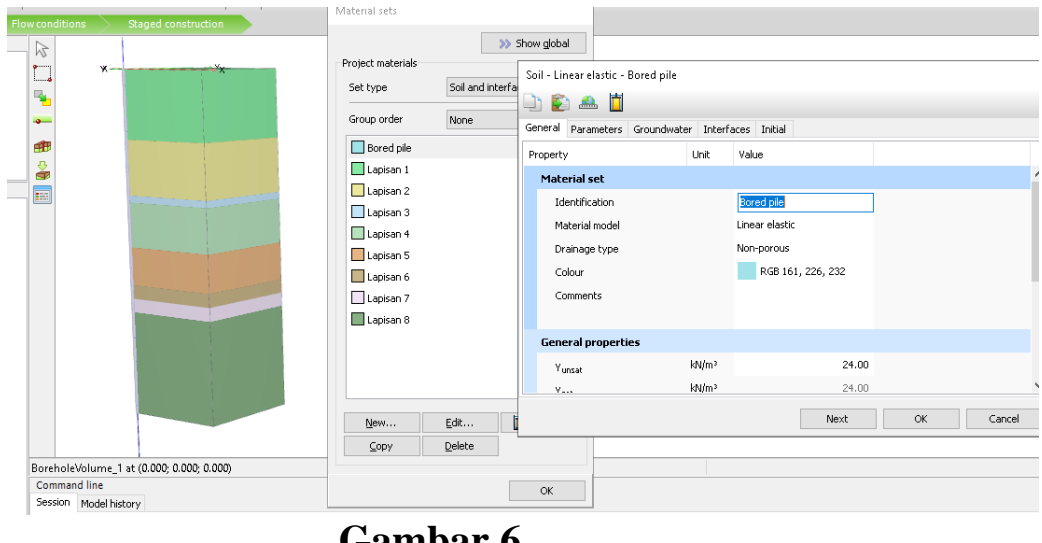

Proses Pemodelan Tanah Dan Input Material

\section{Structure}

Tahapan structure mengakomodasi pemodelan struktur yang termasuk kedalam analisis ini. pada analisis ini dilakukan pemodelan bored pile, elemen interface, dan pembebanan yang akan digunakan sebagai interpretasi pengujian pembebenan pada borepile.

4. Mesh

Tahapan selanjutnya yang harus dilakukan adalah membagi-bagi model struktur dan tanah menjadi elemen-elemen yang lebih kecil. Pada tahapan ini digunkan mesh medium. Mesh yang dihasilkan dari generate mesh medium adalah 
sebanyak 13255 elemen dan 19662 titik nodal. Hasil generate mesh yang dilakukan dapat dilihat pada Gambar 8. Sedangkan untuk mesh fine Jumlah elemen yang dihasilkan adalah 19097 elemen dan 28194 titik nodal (Gambar 9). Dan untuk mesh very fine jumlah elemen yang dihasilkan adalah 38374 elemen dan 55675 titik nodal (Gambar 10).

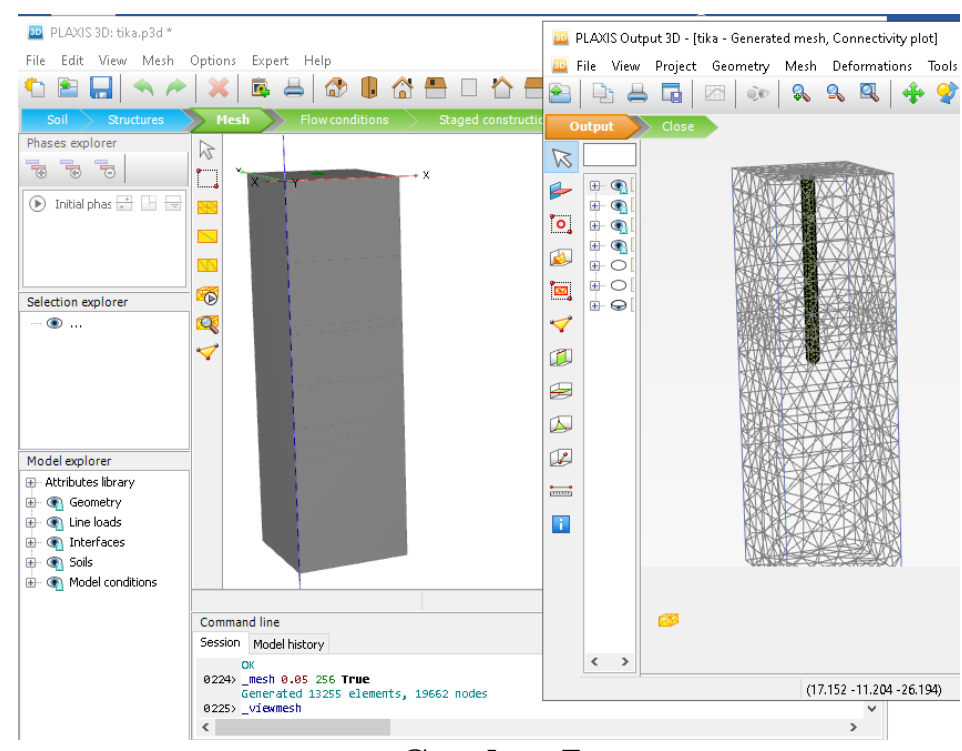

Gambar 7

Hasil Generate Mesh Medium

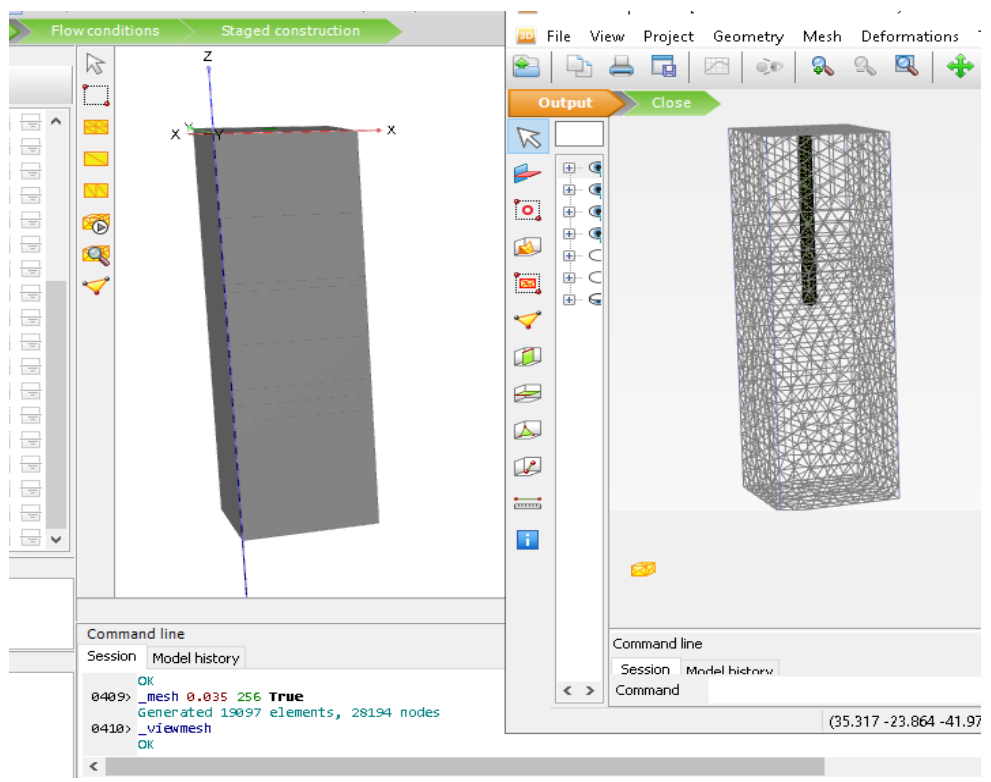

Gambar 8

Hasil Generate Mesh Plaxis 3D dengan Tipe Mesh Fine 


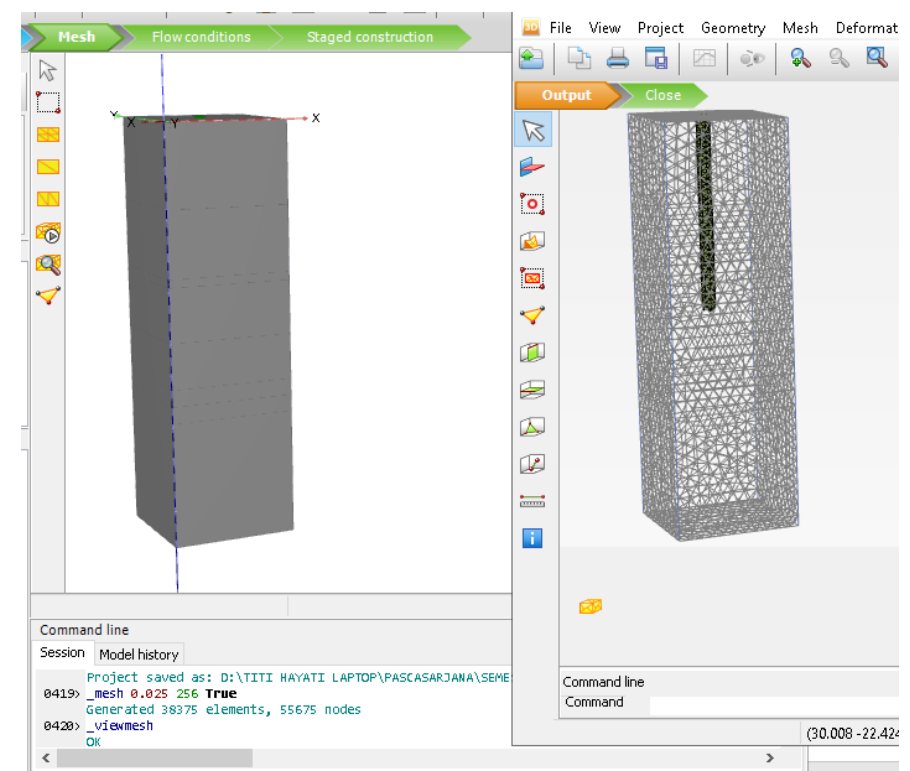

Gambar 9

Hasil Generate Mesh dengan Mesh Very Fine

\section{Stage Construction}

Pada tahapan ini dilakukan pemodelan tahan konstruksi yang menginterpretasi keadaan sebenarnya. Tahapan konstruksi yang dimodelkan pada analisis ini adalah proses pembebanan saat pelaksanaan loading test. Penambahan beban dan waktu yang diinput dalam Plaxis diperoleh dari data loading test di lapangan. Pada analisis ini tahapan konsrruksi yang dimodelkan sebanyak 28 fase (Gambar 11). Setelah tahapan konstruksi dimodelkan dilanjutkan dengan melakukan calculate untuk memulai perhitungan. Hasil perhitungan yang diperoleh disajikan pada Gambar 12.

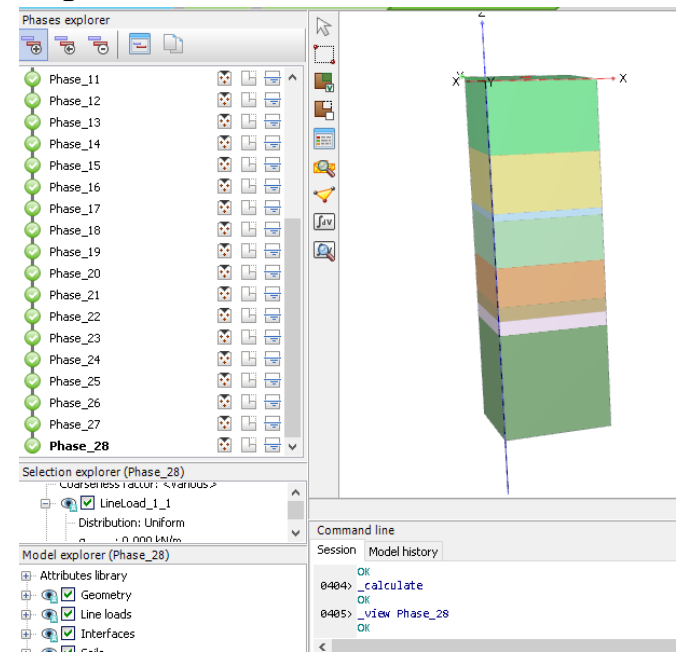

Gambar 10

Pemodelan Tahapan Konstruksi pada Plaxis 3D 


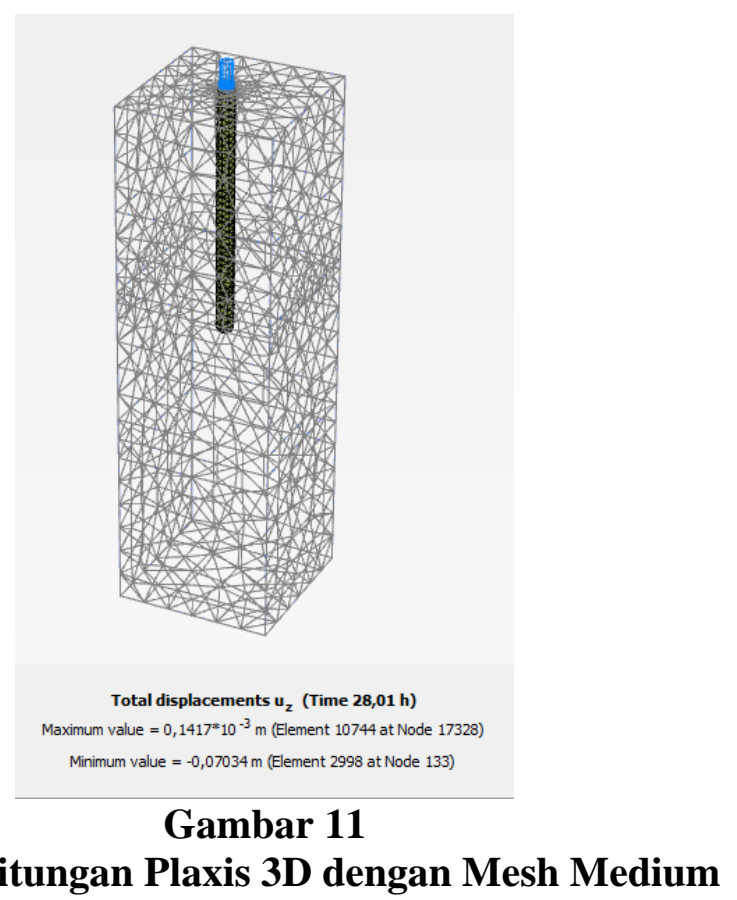

Nilai penurunan juga dihasilkan dari analisis dengan mesh fine dan very fine. Adapun rekapitusi dari nilai penurunan yang dihasilkan oleh ketiga mest tersebut disajikan pada Tabel 6 .

\section{Tabel 6}

Besar Penurunan yang Dihasilkan dari Plaxis 3D

\begin{tabular}{cc}
\hline \multicolumn{2}{c}{ Penurunan Bored pile Tunggal } \\
\hline Metode & Besar Penurunan $(\mathrm{mm})$ \\
\hline Plaxis 3D mesh medium & 70 \\
\hline Plaxis 3D mesh fine & 79 \\
\hline Plaxis 3D mesh very fine & 89 \\
\hline
\end{tabular}

Berdasarkan Tabel 6 dapat dilihat bahwa besar penurunan yang dihasilkan oleh masing-masing mesh memiliki nilai yang berbeda. Semakin kecil bentuk mesh yang dipilih maka semakin banyak elemen yang terbentuk dan semakin besar penurunan yang terjadi.

Besar penurunan berdasarkan hasil loading test di lapangan adalah 4,26 mm (Tabel 1). Besar penurunan yang paling mendekati nilai tersebut adalah besar penurunan berdasarkan analisis Plaxis 3D dengan mesh medium. Sehingga perhitungan daya dukung dilakukan dengan menggunakan data penurunan yang dihasilkan oleh mesh medium pada masing-masing tahapan pemodelan pembebanan. Adapun grafik beban dan penurunan yang dihasilkan dari analisis Plaxis 3D dengan mesh medium pada tahapan pemebebanan disajikan pada Gambar 13. 


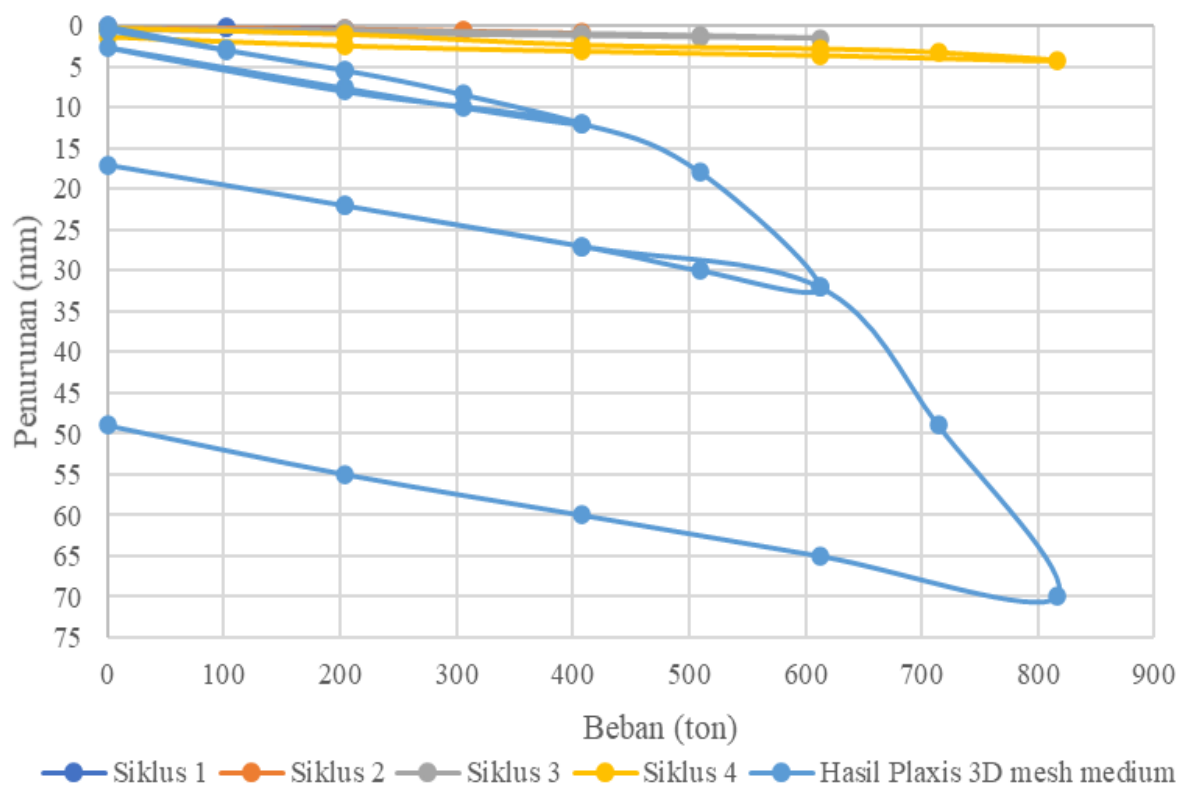

\section{Gambar 12}

Grafik Besar Penurunan Berdasarkan Loading Test dan Hasil Plaxis 3D

Selanjutnya nilai daya dukung dihitung berdasarkan data penurunan tersebut dengan menggunakan metode interpretasi Davisson, Mazurkiewich dan Chin seperti perhitungan yang telah dilakukan sebelumnya pada data loading test.

Adapun nilai daya dukung yang dihasilkan disajikan pada Tabel 7.

\section{Tabel 7}

Daya Dukung Bored Pile Berdasarkan Analisis plaxis 3D

\begin{tabular}{cc}
\hline Metode & Daya Dukung (ton) \\
\hline Davisson & 400 \\
\hline Mazurkiewich & 816 \\
\hline Chin & 766
\end{tabular}

\section{Kesimpulan}

Berdasarkan analisis yang telah dilakukan terdapat perbedaan nilai daya dukung yang dihasilkan dari analisis Plaxis 3D terhadap hasil pengujian loading test di lapangan. Daya dukung bored pile berdasarkan data loading test dengan metode Davisson menghasilkan daya dukung 816 ton, metode Mazurkiewich 950 ton dan metode Chin 761 sedangkan berdasrkan hasil Plaxis 3D, metode Davisson menghasilkan daya dukung 400 ton, Mazurkiewich 816 ton dan metode Chin 766 ton. Dari data tersebut dapat disimpulkan bahwa besar daya dukung yang dihasilkan oleh analisis Plaxis 3D lebih kecil dari pada hasil pengujian di lapangan sehingga analisis ini dapat digunakan untuk proses perencanaan pondasi yang memiliki faktor keamanan terhadap konstruksi di lapangan. 
Analisis Daya Dukung dan Penurunan Pondasi Tiang Bor dengan Plaxis 3D terhadap Hasil Loading Test

Berdasarkan nilai penurunan yang dihasilkan dari analisis Plaxis 3D, pada kasus ini besar penurunan yang dihasilkan dari analisis Plaxis 3D dengan mesh medium memberikan nilai penurunan yang paling mendekati hasil loading test di lapangan. 
Dewi Sartika Hutapea, Roesyanto, Rudi Iskandar

\section{BIBLIOGRAFI}

American Standart Test Method. (2010). Annual Book of ASTM Standart, Section Four Construction, Bar Harbor.Google Scholar

Bowles, J.E. (1997). Analisis dan Desain Pondasi Jilid 2. Jakarta:Erlangga.Google Scholar

Bowles, J.E. (1998). Analisis dan Desain Pondasi, Jilid 2 Edisi Keempat, Jakarta:Erlangga.Google Scholar

Broms, B. B. (1964). Lateral Resintance of Piles in Cohesive Soil. Soil Mechanic and Foundation Division Proceeding of the American Society of Civil Engineer,51.Google Scholar

Das, B. M. (1995). Mekanika Tanah 1. Jakarta: Erlangga.Google Scholar

Das, B.M. (1999). Principle of Foundation Engineering, $4^{\text {nd }}$ Edition, PWS - KENT Publishing Company, Boston.Google Scholar

Fadilah, U. N., dan Tunafiah, H. (2018). Analisa Daya Dukung Pondasi Bored pile Berdasarkan Data N-SPT Menurut Rumus Reese dan Wright dan Penurunan. Jurnal IKRA-IHT Teknologi Vol 2, No. 3, November, 2018. Google Scholar

Hardiyatmo, H. C. (2002). Mekanika Tanah I, Yogyakarta: Gajah Mada University Press.Google Scholar

Hardyatmo, H.C. (2010). Teknik Pondasi, jilid 1 dan 2, Penerbit Gramedia, Jakarta.Google Scholar

Hardyatmo, H.C. (2010). Mekanika Tanah, jilid 1 dan 2, Penerbit Gramedia, Jakarta.Google Scholar

Harsanto, C., dkk. (2015). “Analisa Daya Dukung Tiang Bor (Bored pile) pada Struktur Pylon Jembatan Soekarno dengan Plaxis 3D”, Jurnal Ilmiah Media Engineering, Vol.5, No 2, September 2015Google Scholar.

Indah Sari, Kartika. (2015). Analisis Daya Dukung Bored pile Diameter Satu Meter Dengan Menggunakan Uji Beban Statik dan Menggunakan Model Tanah Mohr Coulomb Pada Proyek Paragon Square Tanggerang Banten, Tesis, Universitas Sumatera Utara, Medan.Google Scholar

Lastiasih, Y. (2013). Reabilitas Daya Dukung Pondasi Tiang Bor Berdasarkan Formula Reese dan Wright dan Usulan Load Resistance Factor Design dalam Perencanaan Pondasi Tiang Bor Studi Kasus Proyek Jakarta. Jurnal MKTS, vol 19. No 2, Desember 2013. Google Scholar 
Analisis Daya Dukung dan Penurunan Pondasi Tiang Bor dengan Plaxis 3D terhadap Hasil Loading Test

Mandasari, F., dan Fauziyah, A. (2019). Analisis Pondasi Bored pile pada Gedung 23 Lantai di Tanah Lempung Daerah Cibubur. Jurnal Ilmiah Desain dan Konstruksi Vol. 18 No 2, Desember 2019 Google Scholar.

Mansur, S., dkk. (2019). Analisa Kapasitas Dukung dan Penurunan Tiang Bor Tunggal Akibat Beban Gempa dengan Menggunakan Plaxis 2D, Seminar Nasional Teknologi, Sains dan Hurmaniora 2019. Google Scholar

Mugiono, A., dkk. (2020). Analisis Perbandingan Daya Dukung Pondasi Tiang Bored pile dari Hasil Tes PDA Berdasarkan Metode Chin, Mazurkiewich dan Davisson. Prosiding KIMU 4, 28 Oktober 2020, ISSN.2720-9180.Google Scholar

Nurmaidah. (2017). Studi Analisis Perilaku Daya Dukung Pondasi Tiang Bor dengan Menggunakan Uji Beban Statik dan Model Tanah Mohr Coloumb pada Proyek Paragon Square Tangerang, Banten”, Jurnal Education Buliding, Vol 3, No 1, Juni 2017.Google Scholar

Octavia, Riki. (2019). Analisis Daya Dukung Dan Penurunan Tiang Tekan Hidrolis Square Pile 50x50 $\mathrm{Cm}^{2}$ Pada Proyek Bangunan Bertingkat Di Pluit Jakarta Utara, Tesis, Universitas Sumatera Utara, Medan Google Scholar.

Poulus, H. G. dan Davis, E. H. (1980). Pile Foundation Analysis and Design. John Wiley and Sons, New York. Google Scholar

Prakasa, A. G. dan Rijaluddin, A. (2016). Analisa Daya Dukung dan Penurunan Pondasi Tiang Bor (Bored pile) Tunggal dengan Menggunakan Program Plaxis, Jurnal EEnsitec: Vol 03, No 1, November 2016. Google Scholar

Prakash, S.H., \&Sharma, D. (1990). Pile Foundations In Engineering Practice, John Willey dan Sons, Inc. Canada. Google Scholar

Schmertman, J. H. (1970). "Static Cone to Compute Settlement Over Sand", ASCE Journal of Soil Mech. And Foundation Division, Vol. 96, No. SM3. Pp.10111043. Google Scholar

Sosrodarsono, S., dan Nakazawa. (2005). Mekanika Tanah dan Teknik Pondasi., PT. Pradya Paramita, Jakarta.Google Scholar

Tanjung, D., dkk. (2019). Analisa Daya Dukung Pondasi Bored pile Tunggal pada Proyek Underpass Katamso Jalan Jenderal Besar A.H. Nasution Medan-Sumatera Utara. Jurnal Buletin Utama Taknik, Vol.15, No.1, September, 2019 Google Scholar 
Dewi Sartika Hutapea, Roesyanto, Rudi Iskandar

\section{Copyright holder :}

Dewi Sartika Hutapea, Roesyanto, Rudi Iskandar (2021)

First publication right:

Jurnal Syntax Admiration

This article is licensed under:

(c) $(\mathrm{C})$ 